\title{
Case Studies for the Statistical Design of Experiments Applied to Powered Rotor Wind Tunnel Tests
}

\author{
Austin D. Overmeyer, ${ }^{*}$ Philip E. Tanner ${ }^{\dagger}$ and Dr. Preston B. Martin ${ }^{\ddagger}$ \\ U.S. Army Aviation Development Directorate (ADD) \\ Aeroflightdynamics Directorate (AFDD) \\ U.S. Army Research, Development, and Engineering Command \\ NASA Langley Research Center, Hampton, VA 23681 \\ Dr. Sean A. Commo $§$ \\ Systems Engineering and Engineering Methods Branch \\ NASA Langley Research Center, Hampton, VA 23681
}

\begin{abstract}
The application of statistical Design of Experiments (DOE) to helicopter wind tunnel testing was explored during two powered rotor wind tunnel entries during the summers of 2012 and 2013 . These tests were performed jointly by the U.S. Army Aviation Development Directorate Joint Research Program Office and NASA Rotary Wing Project Office, currently the Revolutionary Vertical Lift Project, at NASA Langley Research Center located in Hampton, Virginia. Both entries were conducted in the 14- by 22-Foot Subsonic Tunnel with a small portion of the overall tests devoted to developing case studies of the DOE approach as it applies to powered rotor testing. A 16-47 times reduction in the number of data points required was estimated by comparing the DOE approach to conventional testing methods. The average error for the DOE surface response model for the OH-58F test was $0.95 \%$ and $4.06 \%$ for drag and download, respectively. The DOE surface response model of the Active Flow Control test captured the drag within $4.1 \%$ of measured data. The operational differences between the two testing approaches are identified, but did not prevent the safe operation of the powered rotor model throughout the DOE test matrices.
\end{abstract}

\section{Nomenclature}

$14 \times 22 \quad 14-$ by 22-Foot Subsonic Tunnel

$A F C \quad$ Active Flow Control

$B B D \quad$ Box-Behnken Design

$D O E \quad$ Design of Experiments

FCCD Face-centered Central Composite Design

GRMS General Rotor Model System

LaRC Langley Research Center

OFAT One Factor At a Time

SCCD Spherical Central Composite Design

$C_{T} \quad$ Thrust coefficient, $T /\left(\rho V_{\text {tip }}^{2} A\right)$

$\Delta C_{d} \quad$ Percent change in fuselage drag

$\varepsilon f_{e} \quad$ Normalized flat plate drag of fuselage

$\varepsilon L_{e} \quad$ Normalized flat plate download of fuselage

$k \quad$ Number of design space variables

\footnotetext{
* Research Scientist, NASA Langley Research Center, Hampton, VA 23681

${ }^{\dagger}$ Research Scientist, NASA Langley Research Center, Hampton,VA 23681

${ }^{\ddagger}$ Sr. Research Scientist, NASA Langley Research Center, Hampton, VA 23681

${ }^{\S}$ Research Engineer, NASA Langley Research Center, Hampton, VA 23681, AIAA Member
} 


$\begin{array}{ll}P_{h} & \text { AFC horizontal actuators inlet pressure, psi } \\ P_{v} & \text { AFC vertical actuators inlet pressure, } \mathrm{psi} \\ x_{i} & \text { Normalized design space variable } \\ & \\ \alpha & \text { Fuselage pitch angle, degrees } \\ \beta & \text { Fuselage sideslip angle, degrees } \\ \delta & \text { Surface response model coefficients } \\ \mu & \text { Advance ratio, } \approx V / V_{t i p} \\ \xi_{i} & \text { Natural design variable }\end{array}$

\section{Introduction}

Statistical Design of Experiments (DOE) is a rigorous methodology used to plan, execute, and analyze an experiment, (Ref. 1). DOE utilizes various statistical methods and tools to strategically guide the investment of resources prior to an experiment and ensures statistically defendable and objective results at the conclusion. Originally developed for use in the agricultural industry, DOE has been successfully employed in various aerospace applications over the past 15 years (Refs. 2-4). Efficient screening of independent variables and estimation of response surface models are examples of the tangible benefits of the implementation of a DOE approach in experimentation. However, the success of a designed experiment depends on subject-matter expertise to aid in choosing and determining the levels of the independent variables, deciding inferential risks, and interpreting the results.

DOE emphasizes the principles of randomization, replication, and blocking. Randomization describes the order in which the runs are executed in an experiment and is a best practice for reducing dependencies among the observations or measurements. While techniques exist for instances where complete randomization is impractical or unrealistic, randomization protects the responses by averaging extraneous effects that may exist. Replication is the process of independently repeating measurements under a set of identical conditions. It provides an estimate of the pure experimental error, which sets the lower bound for uncertainty. The number of runs required in an experiment may be determined from this estimate, commonly known as sample size calculation. Blocking is used to limit the impact of variables that are not or cannot be controlled during an experiment. Day-to-day variability is a common parameter that can impact the analysis but is generally not of interest during an experiment. An experimental design with blocks can reduce or nearly eliminate the impacts of this potential variability.

Currently, the majority of wind tunnel testing is conducted using a One Factor At a Time (OFAT) approach. The major difference between the OFAT and the DOE approach to experimentation is how interactions between independent variables are considered. OFAT involves modifying the independent variables one-at-a-time whereas DOE typically modifies the independent variables together. As a result, it is possible to detect interaction effects and estimate them in a response surface model. Two-level factorial designs are common in designed experiments where each independent variable is varied simultaneously across two levels: low (-1) and high $(+1)$. For example, a two-level factorial design with $k=3$ independent variables consists of $2^{k}=2^{3}=8$ test conditions, as shown in Figure 1. In this example, the effects of $x_{1}, x_{2}$, and $x_{3}$ as well as the joint effects $x_{1} x_{2}, x_{1} x_{3}$, and $x_{2} x_{3}$ can be determined and estimated. For experiments with more than five independent variables, a fraction of all possible factorial combinations can be run to improve the execution efficiency.

During wind tunnel test planning, the researcher is required to prioritize the test objectives to fit within the resources available. Undoubtedly, all possible combinations of the independent variables cannot be tested within the allotted time frame. Recent budget cuts and fiscal uncertainty has created an increased focus on the researcher to maximize productivity while minimizing cost. Due to the inherently complex nature of powered rotor wind tunnel testing, windon rates (the ratio of testing time to tunnel occupancy time) are generally much lower than their fixed-wing or isolated fuselage counterparts. This increased complexity is related to the routine maintenance required on a powered model and the increased number of personnel needed to operate the model. For example in the 14- by 22-Foot Subsonic Tunnel (14x22) at NASA Langley Research Center (LaRC), it is not uncommon for a standard fixed-wing test to have a $50-70 \%$ wind-on rate compared to a powered rotor test rate of $25 \%$.

In an effort to improve testing efficiency and reduce uncertainty error, two powered rotor wind tunnel tests were conducted using both OFAT and DOE test matrices. The first test was of a $37.7 \%$ scale model of an OH-58F to update the flight performance models and investigate potential interactional aerodynamic issues for the new F-model aircraft. The second test was a generic transport class fuselage with Active Flow Control (AFC) used for the reduction of fuselage drag and download. The primary objectives of both tests were met using standard OFAT testing principals. 
Near the end of each test entry, a DOE approach was used to form case studies. By replacing the OFAT test matrix with a DOE test matrix, direct comparisons between both methods could be used to aid in future test planning.

\section{Tests Description}

To gain confidence in the DOE methodology as it applies to powered rotor testing, the method was implemented during two powered rotor wind tunnel entries at the 14x22 at NASA LaRC during the summers of 2012 and 2013. These two tests formed case studies to provide understanding of the operational and methodological differences between DOE and OFAT test approaches as they apply to powered rotor testing. Standard OFAT test matrices were conducted throughout the majority of both wind tunnel entries. The design spaces formed by the OFAT test matrices were then repeated using a DOE test matrix approach. By repeating design space, the models developed using DOE could be directly compared to the experimental results obtained using OFAT.

\section{A. 14- by 22-Foot Subsonic Tunnel}

The 14x22 is a $770 \mathrm{ft}$ closed circuit, single return, atmospheric wind tunnel (see Fig. 2). The tunnel was constructed in 1970 to provide improved understanding of the aerodynamics of Vertical/Short Take-Off and Landing (V/STOL) aircraft (Ref. 5). The 14×22 is currently used to assess aerodynamic performance for low-speed tests of powered and unpowered fixed wing and rotorcraft models over a wide range of takeoff, landing, cruise, and high angle-of-attack conditions. A sketch showing the major components of the tunnel is presented in Fig. 3, as configured for the OH-58F test. All of the stations presented are referenced to the beginning of the test section in feet. For tunnel calibration and repeatability checks, a probe was placed at the standard model location in the empty tunnel $(17.75 \mathrm{ft}$, marked by the red line in the figure) during check-standard testing. See Ref. 5 for more details.

\section{B. General Rotor Model System (GRMS)}

For both tests, the General Rotor Model System (GRMS) was used. The GRMS is a rotor drive system that can be fully enclosed within a fuselage shell. As described by Murrill (Ref. 6), the system is powered by two $75 \mathrm{hp}$ water-cooled variable frequency electric motors and is capable of driving a rotor up to $13.2 \mathrm{ft}$ in diameter through either a 5.47:1 high-speed transmission or a 6.90:1 low-speed transmission. Cooling for the motors is provided by an external water chiller, and lubrication for the transmission was supplied from an external lube cart. Two internal six-component strain gage force and moment balances are used for measuring the fuselage and rotor aerodynamic loads separately.

\section{OH-58F Test Case Study}

For the OH-58F test, the GRMS was enclosed in a 37.7\% scale model of the aircraft, powering a similarly-scaled rotor, and is shown in the standard mission configuration in Fig. 4. The full test involved a large number of configuration changes and advanced measurement techniques, (Ref. 7). The focus of this paper is on the measured fuselage drag and download values in the mission configuration throughout the flight envelope.

First, an OFAT test matrix was run for the OH-58F to serve as the baseline for comparison to the DOE surface response model. The matrix was a single run with a total of 24 points and consisted of sweeps in forward speed $(\mu)$, fuselage sideslip angle $(\beta)$, and fuselage angle of attack $(\alpha)$, with each variable changed independently at constant rotor thrust $\left(C_{T}=0.007\right)$. The run schedule for the baseline OFAT OH-58F testing is summarized in Table 1 in the Appendix.

The DOE test matrix used the four independent variables to create a 4-D design space that consisted of 46 points. To complete the design space tested with the DOE process using an OFAT test matrix, 2184 points would have been required. Thus, the DOE test matrix required only $2 \%$ of the total number of points for the same design space. The number of OFAT points was calculated from possible combinations of the independent variables: $C_{T}=6, \alpha=7, \beta=13$, $\mu=4$.

\section{AFC Test Case Study}

For the AFC test, the GRMS was enclosed by the ROBIN-mod7 fuselage with the aft ramp housing fluidic actuators used for drag and download reduction. Details of the test are included in Ref. 8 and a photograph of the model is shown in Fig. 5. The aft ramp consisted of three independent zones of the fluidic actuators as displayed in Fig. 6. In each zone, the input pressure could be controlled independently. For the DOE portion of the test, the three zones were 
restricted to a vertical zone $\left(P_{v}\right)$ formed by $P_{1}$ and $P_{3}$ and a horizontal zone $\left(P_{h}\right)$ formed by $P_{2}$. The 4-D DOE design space included the actuator vertical and horizontal pressures in addition to the fuselage pitch $(\alpha)$ and advance ratio $(\mu)$.

Only the percent drag change results were explored during this effort. The percent drag change for the DOE test matrix was calculated by measuring the drag change with the actuators on/off at each test condition. The DOE test matrix consisted of 29 test conditions; therefore, 58 data points were required to determine the percent drag change.

During data processing, it was determined that additional test conditions were required to supplement the original DOE test matrix to create an accurate third order model. An additional 67 test conditions from the OFAT were used to create the DOE surface response model for a total of 96 test conditions. While the increase in the number of test conditions required was significant it was only $6 \%$ of the total number of test conditions required to cover the design space using OFAT. For the OFAT test matrix, 1536 test conditions would have been required. The number of test conditions was calculated from possible combinations of the independent variables: $\mu=4, \alpha=6, P_{v}=8, P_{h}=8$.

\section{DOE Model Description}

Before selecting a design for the $\mathrm{OH}-58 \mathrm{~F}$ and $\mathrm{AFC}$ tests, a form of the mathematical relationship between the responses and the independent variables was assumed. The postulated model for both tests was based on a secondorder Taylor-series expansion for $k$ independent variables and is given by

$$
y=\delta_{0}+\sum_{i=1}^{k} \delta_{i} x_{i}+\sum \sum_{i<j=2}^{k} \delta_{i j} x_{i} x_{j}+\sum_{i=1}^{k} \delta_{i i} x_{i}^{2}
$$

This model form is common in response surface applications and was considered to be an adequate representation based on expertise and historical data.

The $x$ variables in Eq. (1) represent normalized values of the independent variables based on the range of each independent variable in natural or engineering units. The conversion between normalized and natural units was done by

$$
x_{i}=\frac{2 \xi_{i}-\max \left(\xi_{i}\right)+\min \left(\xi_{i}\right)}{\max \left(\xi_{i}\right)-\min \left(\xi_{i}\right)}
$$

where $x_{i}$ is the normalized variable and $\xi_{i}$ is the variable in natural units. Because of the normalization, it was possible to compare the magnitudes of the regression coefficients to determine relative impact of the independent variables on the responses.

\section{A. OH-58F DOE Design}

The effect of fuselage angle of attack $\left(\alpha, x_{1}\right)$, fuselage sideslip angle $\left(\beta, x_{2}\right)$, advance ratio $\left(\mu, x_{3}\right)$, and thrust coefficient $\left(C_{T}, x_{4}\right)$ on download and drag were varied across low (-1) and high $(+1)$ values to understand the impact on the download and drag during the $\mathrm{OH}-58 \mathrm{~F}$ test. The ranges, in engineering units, of each independent variable are given in Table 2. Eq. (1) as the assumed model form, two designs were proposed that supported estimation of the fifteen model parameters, which are the first and second order terms plus the intercept. The spherical central composite design (SCCD) and face-centered central composite design (FCCD) shared a common center and set of axial points, as shown in Figure 7. The difference in the two designs is in the location of the factorial points. A factorial combination is when all of the independent variables are active $\left(x_{i} \neq 0\right)$. For the SCCD, the factorial points were located at a distance of 1.4 normalized units from the center of the design space whereas the FCCD factorial points were located 2 normalized units from the center. As a result, the flight parameters were more extreme in the FCCD. While each design was sufficient for estimating the parameters in the mathematical model, the low cost to execute both designs led to the decision to use the SCCD and the FCCD. Replicates were run with the four independent variables at their nominal levels to the experimental error, or noise, in the data. The combination of the two designs permitted estimation of higher-order (third-order) effects that were not assumed in the original model.

\section{B. AFC DOE Design}

For the AFC test, angle of attack $\left(\alpha, x_{1}\right)$, advance ratio $\left(\mu, x_{2}\right)$, vertical actuator pressure $\left(P v, x_{3}\right)$, and horizontal actuator pressure $\left(P h, x_{4}\right)$ were varied to observe the impact on drag. Using Eq. (1) as a starting point, a Box-Behnken design (BBD) was selected as a baseline. BBDs, shown in Figure 8, are another popular design for second-order response surface applications Ref. 9. For $k=4$ factors, the BBD is a combination of six (6) blocks where two (2) 
factors are varied through a two-level factorial design. With a center point, the four-factor BBD contains twenty-five (25) unique runs. BBDs are also appealing because the factor settings are less extreme than those in a CCD because only a subset of the factors are active. However, the BBD for the AFC test was slightly modified to eliminate factor combinations not of interest, such as low advance ratio with the horizontal actuator pressure at its low setting. This modification was done with minimal impact to the estimation of the model. Replicate points were included at factor combinations of high interest. The resulting design contained twenty-nine (29) points, which was an improvement in efficiency over the CCD. The BBD design was not selected for the $\mathrm{OH}-58 \mathrm{~F}$ because the BBD design is inherently less powerful at determining the interactional coefficients at the corners of the design space, which was a requirement for the $\mathrm{OH}-58 \mathrm{~F}$ test.

\section{Results}

To quantify the accuracy of DOE as used during these case studies, the developed models were compared to the results measured using OFAT run schedules. The results for each case study are compared in the following sections.

\section{A. OH-58F Results}

The developed surface response model for the $\mathrm{OH}-58 \mathrm{~F}$ was compared to the baseline data acquired using an OFAT test matrix. The DOE surface response model coefficients are given in Table 4 in the Appendix. The drag was modeled using only second-order terms, while the download was modeled using third-order terms. The third-order coefficients could be calculated because the DOE test matrix was a combination of SCCD and FCCD second-order designs. The normalized equivalent flat plate drag and download is shown in Figures 9(a) and 9(b) for fuselage pitch and sideslip angles, respectively. The solid lines are the DOE surface response model and the dashed lines represent the model confidence region calculated using the average standard deviation of the model. The points are the measured drag and download values from an OFAT test matrix run and the error bars are the experimental error estimated using the balance accuracy values. In general, both the drag and download models are very good. The results are summarized in Table 5 in the Appendix. For this run, the maximum error of the surface response model is $5.67 \%$ and $7.75 \%$ for drag and download, respectively. The average error is $0.95 \%$ and $4.06 \%$. The maximum error values occur at small or zero model attitude in both pitch and sideslip where the dimensional values of drag and download are small compared full-scale range of the balance.

A key advantage of the DOE over OFAT approach is the ability to develop data points at off-nominal test conditions. The surface response model creates a $k$-dimensional volume of data rather than discretized plots at nominal conditions. If a single thrust condition is selected within the 4-D design space, $C_{T}=0.007$, a 3-D volume of normalized flat plate equivalent drag, $\varepsilon f_{e}$, versus advance ratio, pitch angle and sideslip can be generated. Five slices of the data volume are shown in Fig. 10. The points in the figure represent conditions that data were acquired within the DOE test matrix. The fuselage drag is asymmetric with the drag being higher nose right, negative $\beta$, than nose left. The asymmetry is pronounced at higher flight speeds and nose down, negative $\alpha$, attitude. The asymmetry in the drag is expected due to asymmetry of the mission equipment arrangement on the aircraft, see Fig. 4. Obtaining this type of data volume using a standard OFAT matrix would require a minimum of 364 data points compared to the 46 points required using DOE. However, it is not a one-to-one comparison since the DOE surface response model includes data at six thrust conditions or 2184 total data points. This equates to a 47 times (2184/46) reduction in the number of data points required. The OH-58F DOE run of 46 points required 2.5 hours to complete, or approximately 3 minutes per point. The amount of data acquired was equal to 117.5 hours of run time or 710 hours of tunnel time, assuming a wind-on rate of $25 \%$.

\section{B. AFC Results}

The percent change in drag coefficient, $\Delta C_{d}$, for the AFC test was compared to the baseline data acquired using an OFAT test matrix. The OFAT change in drag coefficient data is presented in Fig. 11(a). The percent change in drag shows a step change above approximately $7 \mathrm{psi}$ on both the horizontal and vertical actuator pressures. The step change is a result of the minimum pressure required to achieve the instability required to cause the actuator to oscillate. Below approximately $7 \mathrm{psi}$, it has been shown by hotwire velocity measurements that the actuator produces steady blowing biased to one side of the actuator exit. As a result of this step change, additional data points from the initial DOE test matrix were required to capture the percent drag change response. These additional data points were selected when the horizontal and/or vertical pressure was approximately equal to 7 psi. A total of 67 additional points were added from the OFAT test matrix to supplement the DOE test matrix to develop the surface response model. 
The developed surface response model for the AFC case study was used to generate a contour plot, shown in 11(b), at $\alpha=-3.5^{\circ}$ and $\mu=0.30$ in comparison to the data acquired using OFAT shown in 11(a). The OFAT data acquired and the surface response model data are shown in Table 7 in the Appendix. The maximum and minimum percent difference was $1.7 \%$ and $-4.1 \%$, respectively with a standard deviation of 1.4 . A total of 214 data points were acquired within the design space of the DOE surface response model. Of the 214 data points, 96 data points were used to create the surface response model. The average standard deviation over the entire design space was 1.22.

The coefficients of the AFC surface response model are shown in Table 6 in the Appendix. The coefficients are a useful way to analyze the data to better understand the interaction of each variable. For instance, the first order terms show that the horizontal actuator pressure, $P_{h}$, has no effect on the percent drag change but it is highly dependent on the vertical pressure, $P_{v}$ in the first order. Again in the first order, the change in model pitch, $\alpha$, accounts for approximately one-third of maximum achievable drag reduction.

The response surface model was also used to generate the contour plots of the percent drag reduction as a function of advance ratio, $\mu$, and fuselage pitch, $\alpha$. The contour plots are shown in Fig. 12 for a constant vertical actuator pressure, $P_{v}=20 \mathrm{psi}$, and increasing $P_{h}$ from 5 to $20 \mathrm{psi}$ in 5 psi increments in Figs. 12a-d, respectively. The general trend is that the percent drag reduction decreases with increasing advance ratio and nose up fuselage pitch. In the case of advance ratio, the reduction is a result of reduced actuator authority at higher speeds and an increase in the baseline drag value. For nose up pitch, the decrease in percent drag reduction is a result of small baseline drag value where active flow control may not be required. At horizontal actuator pressures of 5 and 20 psi, Fig. 12a and Fig. 12d, the percent download reduction are nearly identical. At the lowest advance ratio and largest nose down fuselage pitch, a horizontal actuator pressure of 5 and 20 psi yielded the largest reduction in percent drag reduction. For the highest advance ratio and zero fuselage pitch, a horizontal actuator pressure of 15 psi caused the largest reduction in percent drag reduction.

The ability to determine the optimal actuator configuration as a function of flight condition without running of the possible actuator configurations at each flight condition is a substantial time savings. It is difficult to determine a numerical metric on the exact time savings since it is a function of the step selected for each independent variable. However, if coarse step sizes are selected, a conservative estimate of 1536 data points would be required to cover the design space of the AFC DOE surface response model. Compared to the 96 data points required for the DOE testing; therefore, a 16 times reduction in the number of data acquired could have been realized.

\section{Discussion}

The execution of a DOE test matrix with a powered model is quite different than an OFAT test matrix. The entire test team, which consisted of: the test director, model/tunnel operators and safety of flight station monitor, were required to have increased situational awareness due to multiple changes in the independent variables for each test point. The notable operational differences were:

\section{Independent variable tolerance}

It is important to set tolerances for each independent variable so that the model and tunnel operators can efficiently meet the intended test condition. During the OH-58F testing (the first of the two test cases), the model and tunnel operators were attempting to adhere to the independent variable tolerances defined during OFAT testing. Such precision tended to eliminate the time-savings desired with a DOE testing approach without improving the accuracy.

\section{Combined static/dynamic loads}

When simultaneously varying all of the independent variables, the model may be in a combined loading condition outside of the previously explored operational envelope. For static loads, the combination of the independent variables may exceed the static load limits of the balance. For powered rotor testing, where rotor wake effects can be highly non-linear, unexpected dynamic loading may be experienced at unique combinations of the independent variables. Additionally, the model system dynamics could be a function of the model attitude. The test director and the safety of flight station monitor must be in close communication throughout model attitude, tunnel speed and rotor trim condition changes to ensure safe operation throughout a DOE test matrix.

3. Inability to easily distinguish data trends real-time

When operating an OFAT test matrix, it is inherently easy to distinguish the dependent variable response as a function of the independent variable. By design, the DOE couples several independent variables making it difficult for the researcher to identify the independent variable coupling prior to creating the response surface 
model. The researcher must instead rely on the method/process rather than the immediate results. It should be noted that with sufficient planning a response surface model can typically be generated within a few hours of the data being acquired. By generating the response surface model prior to the end of the test, confirmation points can be performed to validate the model.

The two case studies also offered some lessons learned that can be applied to future wind tunnel tests. To create an accurate surface response model with a small number of data points, it is important for the researcher to understand the design space and identify regions in the design space that may be non-linear. This was highlighted by the additional points required for the AFC surface response model to capture the step change in actuator performance. This is analogous to a drag bucket or lift curve stall response for an airfoil test. With the proper planning, these non-linear and/or step changes can be accounted for by understanding their approximate locations within the design space.

\section{Conclusions}

Two case studies of DOE testing approaches were completed for powered rotor testing in the $14 \times 22$ wind tunnel during the summers of 2012 and 2013. The case studies compared the generated DOE surface response models to data acquired using standard OFAT test matrices. The study also compared the operational differences of the two approaches as it applies to powered rotor testing.

The OH-58F DOE test matrix of 46 points required approximately 2.5 hours to complete, but the amount of useful data was equal to approximately 117 hours of run time or 710 hours of tunnel time, assuming a wind-on rate of $25 \%$. The maximum error of the surface response model was $5.67 \%$ and $7.75 \%$ for drag and download, respectively. The average error was $0.95 \%$ and $4.06 \%$.

For the AFC case study, a 16 times reduction in the number of points could have been realized for the design space explored with the DOE test matrix. A total of 214 OFAT data points were compared to the DOE surface response model with a maximum error of $4.1 \%$ and a standard deviation of 1.22 .

Operationally, three key differences between OFAT and DOE testing were identified. The differences were related to variable tolerance, combined loadings and real-time data trends. The operational differences did not prevent safe operation of the test, but did require increased situational awareness of the entire test team.

Based on the results of these case studies, DOE methodology will certainly be applied to future U.S. Army powered-rotor wind-tunnel testing efforts. The researchers and tunnel staff gained valuable experience operating a power rotor model through a DOE test matrix. The AFC case study highlighted the need for confirmation points to validate the DOE surface response models, but ultimately an accurate surface response model was generated. The potential time savings of a DOE methodology, while maintaining accuracy, is too great to ignore.

\section{Acknowledgments}

This project was supported jointly by the U.S. Army and the NASA Subsonic Rotary Wing Project Office, and the support of Susan Gorton is gratefully appreciated. The forced oscillation testing by Dr. Brendon Malovrh was a critical aspect to the powered rotor testing on the mast and sting configurations. The support of the $14 \times 22$ Wind Tunnel staff led by Frank Quinto, and of the test engineers, Josh Ballard, Derry Mace, Jim Byrd, Les Yates, and Greg Markowski was instrumental to this effort. Operation and maintenance of the GRMS was led by Bryan Mann and the test programs were led by Dr. Oliver Wong, Dr. John Berry, Kevin Noonan, and Wayne Mantay. All of these efforts were critical to the success of the project.

\section{References}

\footnotetext{
${ }^{1}$ Montgomery, D., Design and Analysis of Experiments, John Wiley \& Sons, Inc., Hoboken, N.J., 6th ed., 2006, pp. 12-14.

${ }^{2}$ Commo, S. A. and Parker, P. A., Statistical Engineering Perspective on Planetary Entry, Descent, and Landing Research, 2012,24 (2), 306-316.

${ }^{3}$ Landman, D., Simpson, J., Vicroy, D., and Parker, P., "Response Surface Methods for Efficient Complex Aircraft Configuration Aerodynamic Characterization," Journal of Aircraft, Jan 10-13 2007, 44 (4), 1189-1195.

${ }^{4}$ Rhew, R. D. and Parker, P. A., "A Parametric Geometry Computational Fluid Dynamics (CFD) Study Utilizing Design of Experiments(DOE)," U.S. Air Force T\&E Days (pp. 1-13), Destin, FL, 2007.

${ }^{5}$ Gentry, G., Quinto, P., Gatlin, G., and Applin, Z., "The Langley 14- by 22-Foot Subsonic Tunnel Description, Flow Characteristics, and Guide for Users," NASA TP-3008, 1990.

${ }^{6}$ Murrill, R., "Operation and Maintenance Manual for the General Rotor Model System,” SER-50986, NAS1-12674, May 1977.
} 
${ }^{7}$ Tanner, P., Martin, P., and Ballard, J., "Design of a 37.7\% Scale OH-58F Kiowa Warrior Wind Tunnel Test Model Experiment," American Helicopter Society 69th Annual Forum, Phoenix, AZ, May 2013.

${ }^{8}$ Martin, P., Overmeyer, A., Tanner, P., Wilson, J., and Jenkins, L., "Helicopter Fuselage Active Flow Control in the Presence of a Rotor," American Helicopter Society 70th Annual Forum, Montreal, Canada, May 2014.

${ }^{9}$ Myers, R., Montgomery, D., and Anderson-Cook, C., Response Surface Methodology, 3rd ed., 2009.

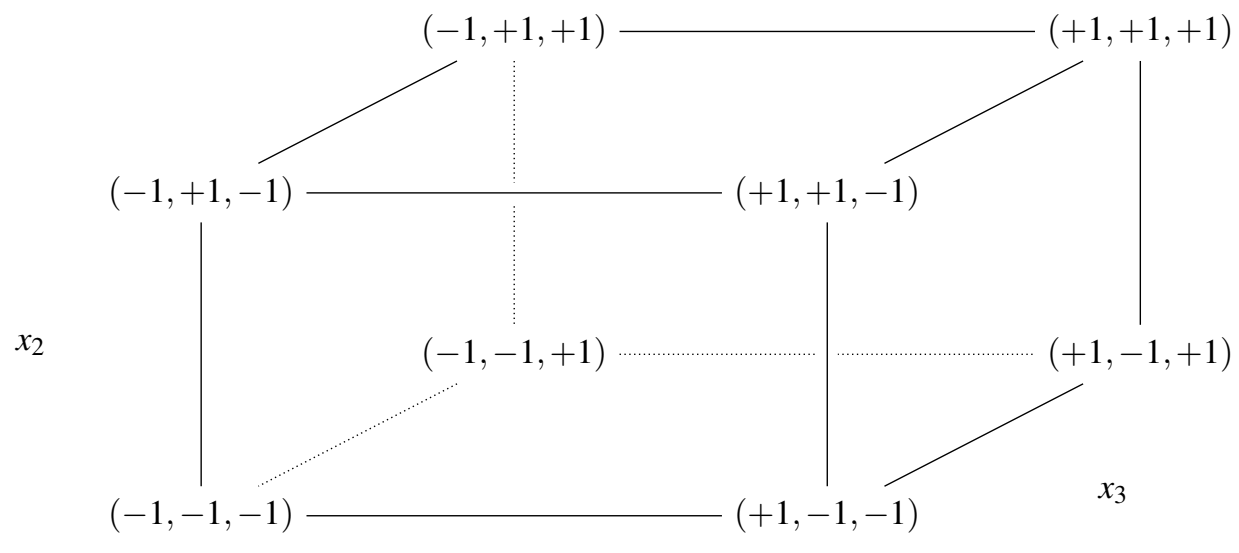

$x_{1}$

Figure 1: Two-level factorial design for $k=3$ independent variables.

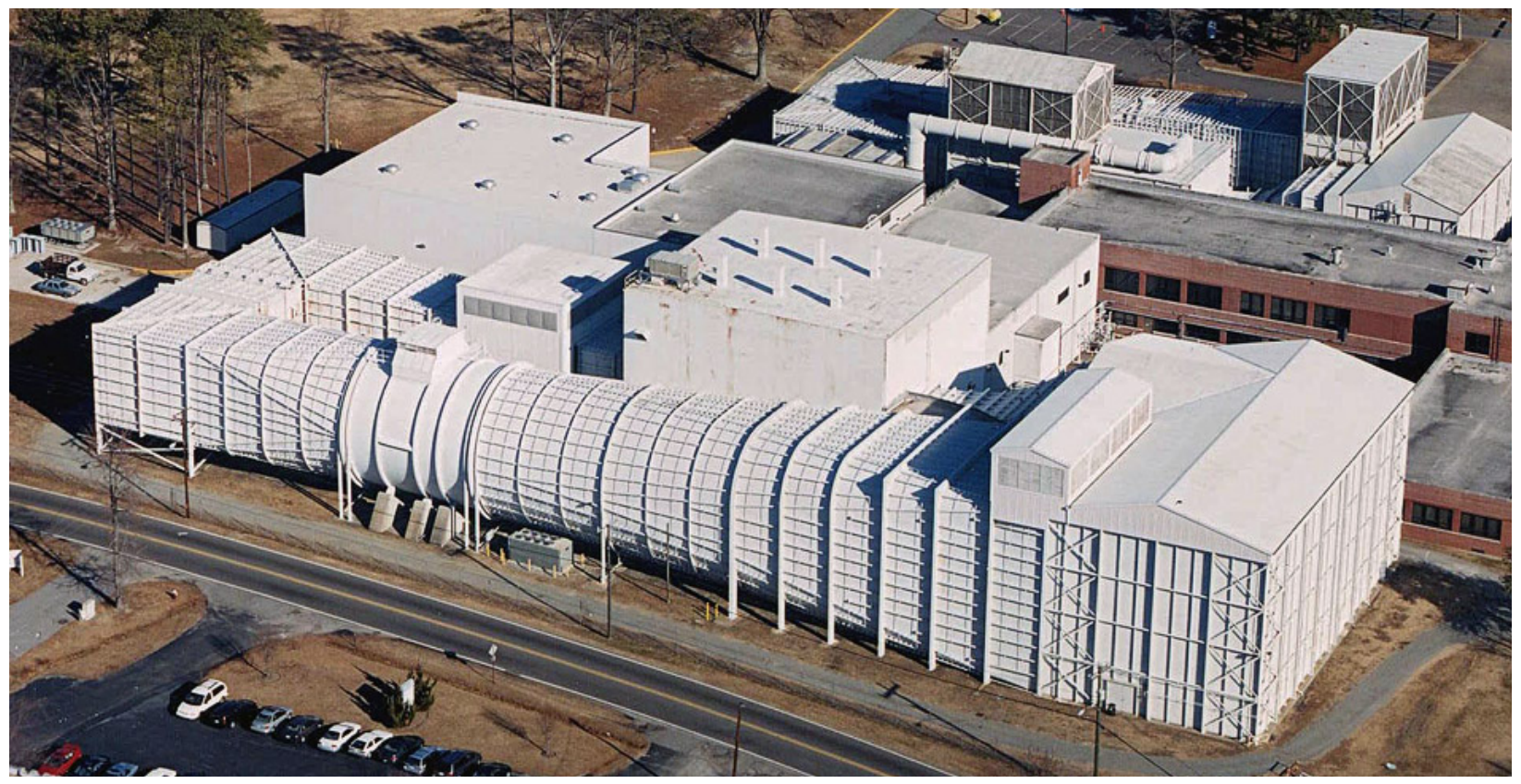

Figure 2: NASA Langley 14- by 22-Foot Subsonic Tunnel. 


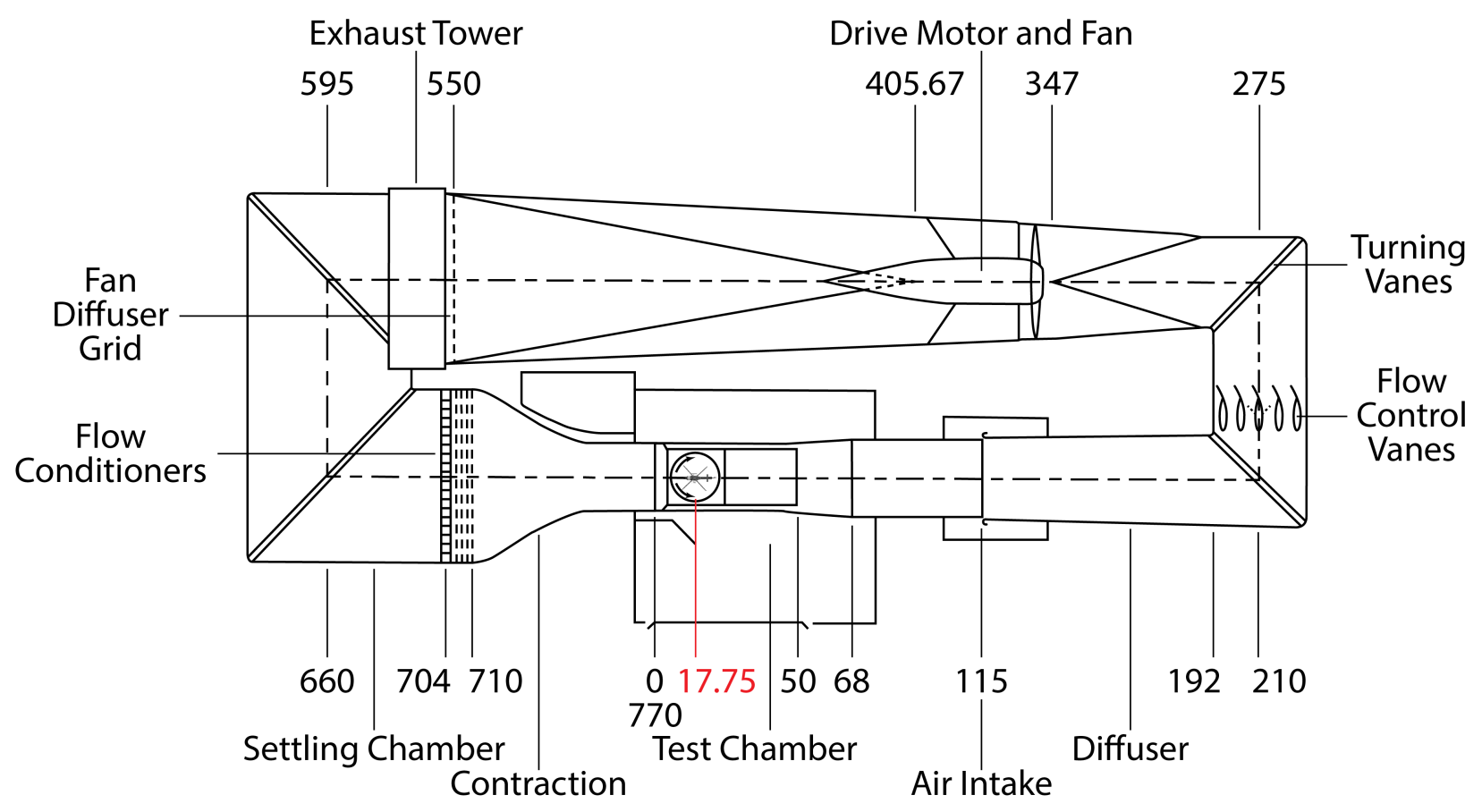

Figure 3: NASA Langley 14- by 22-Foot Subsonic Tunnel circuit.

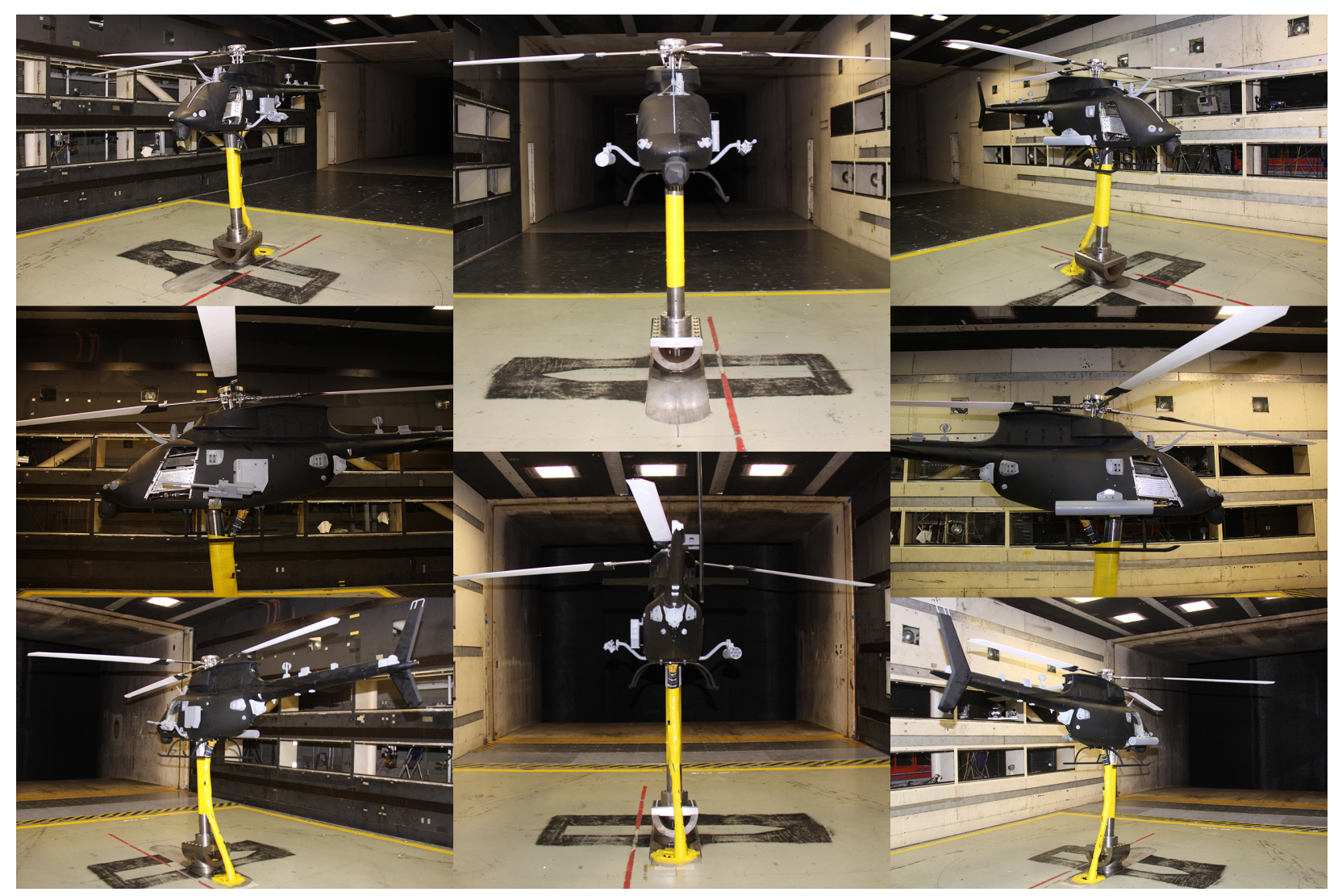

Figure 4: OH-58F 37.7\% Model, Mission Configuration, in 14x22. 


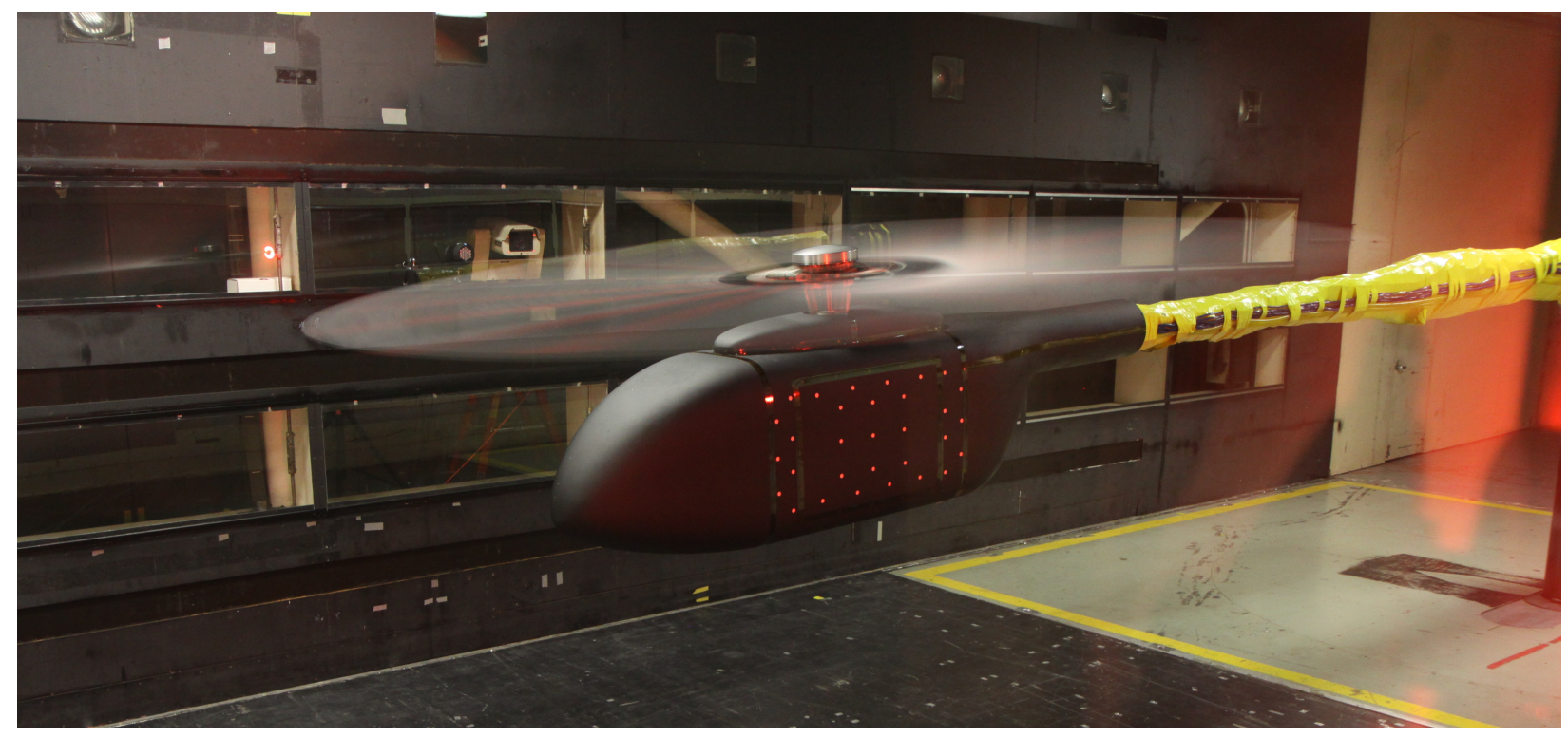

Figure 5: Active Flow Control Model in 14x22.

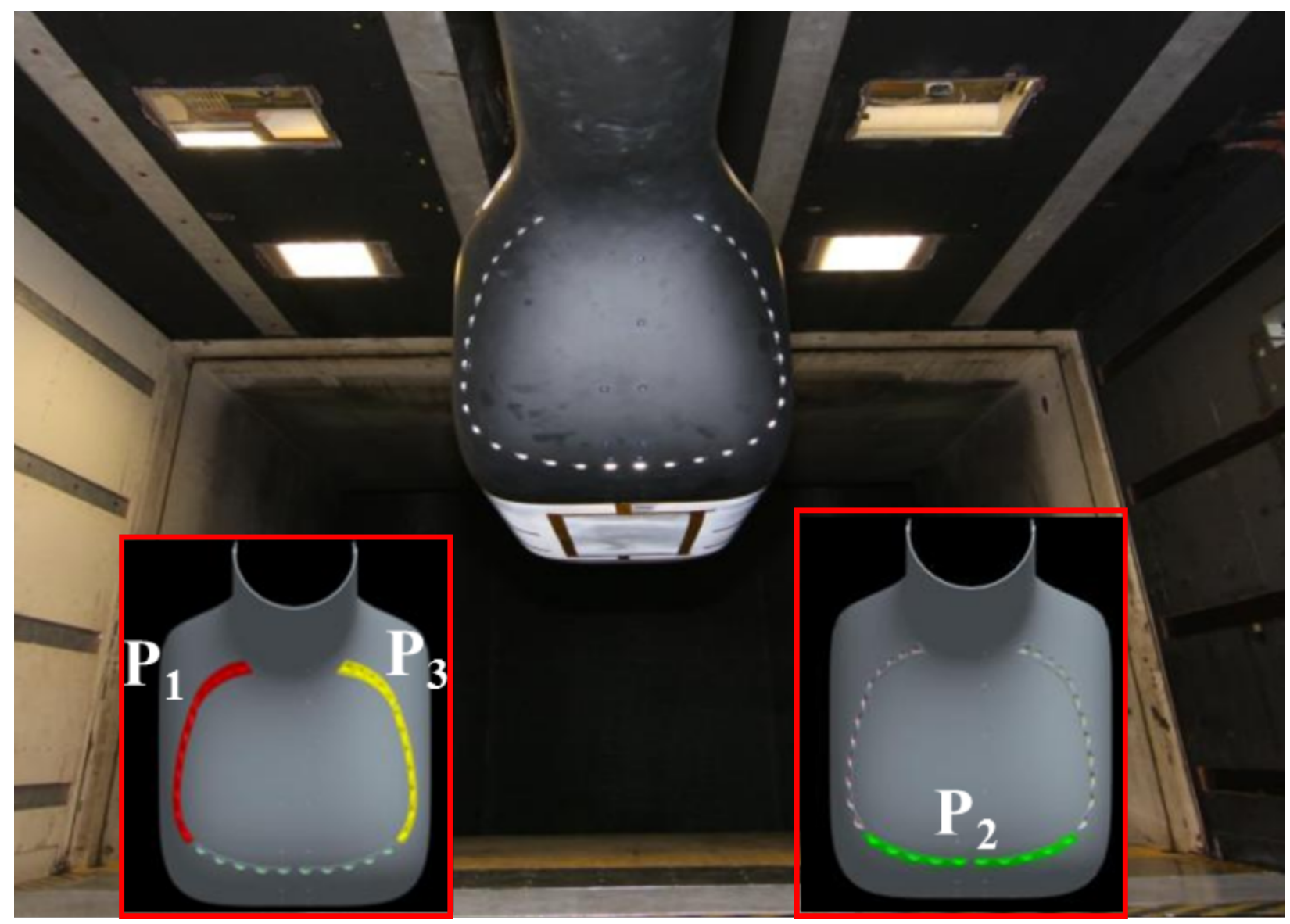

Figure 6: Three actuator zone layouts on the fluidic ramp section of the fuselage (view: upstream, aft end of fuselage). 


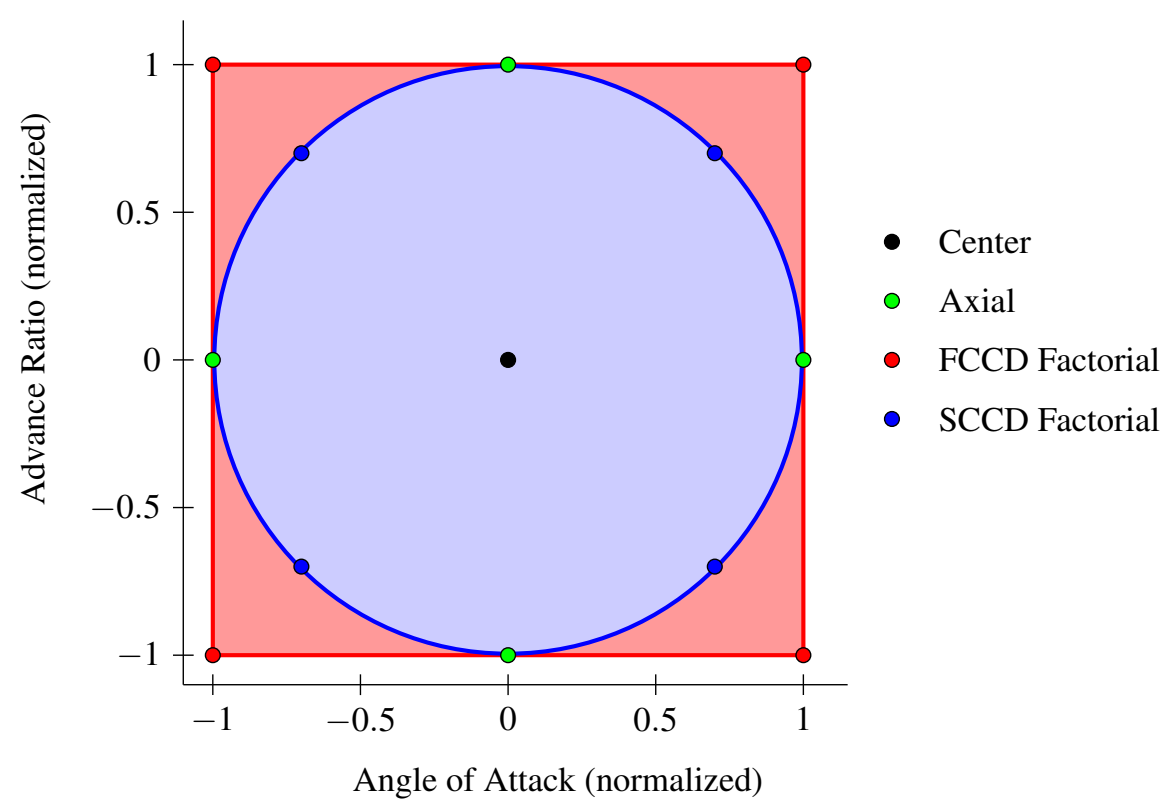

Figure 7: OH-58F Design Space - Advance Ratio vs. Angle of Attack.

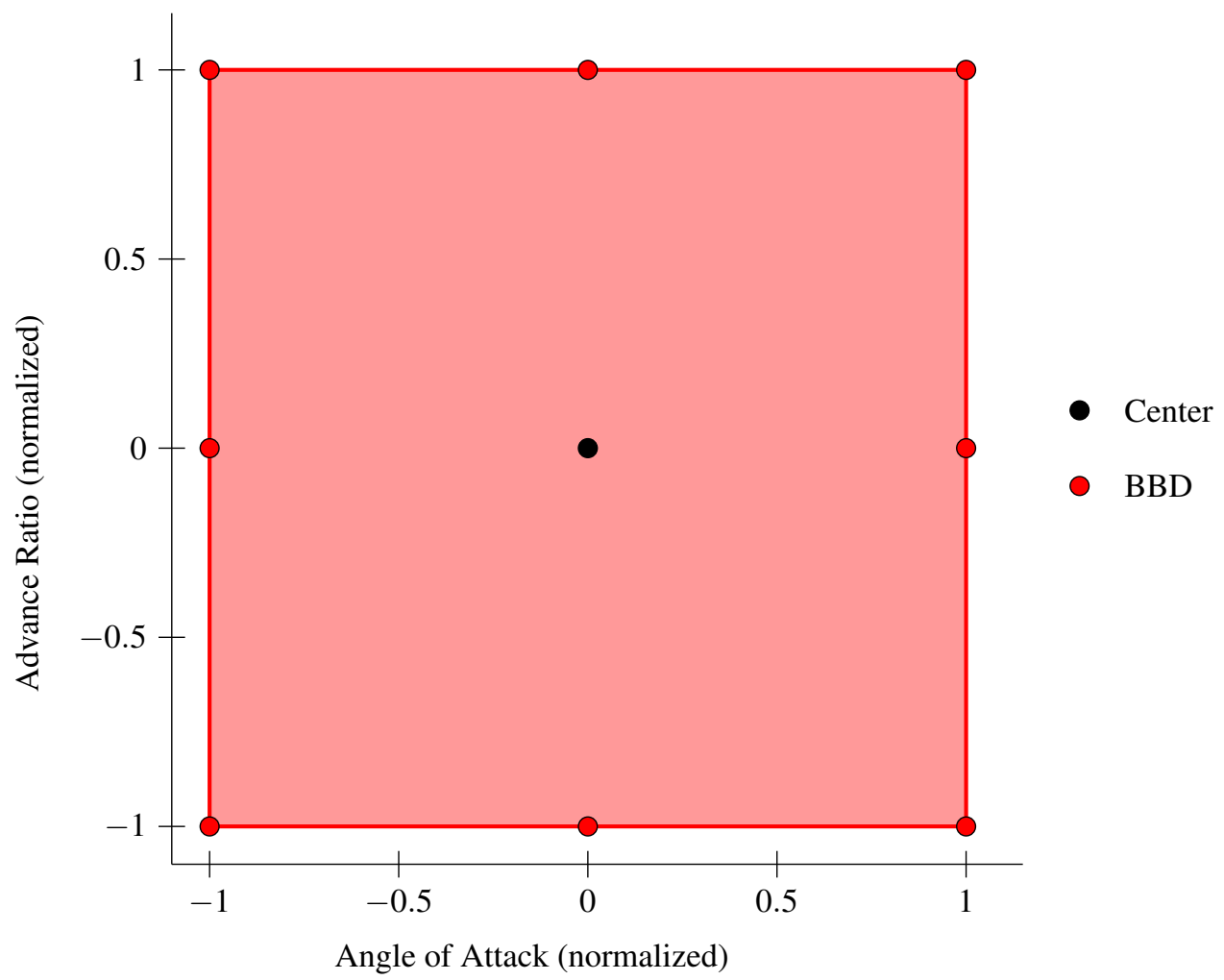

Figure 8: AFC Design Space - Advance Ratio vs. Angle of Attack. 
$\mu=0.30 \quad \mathrm{C}_{\mathrm{T}}=0.007 \quad \beta=0.0$

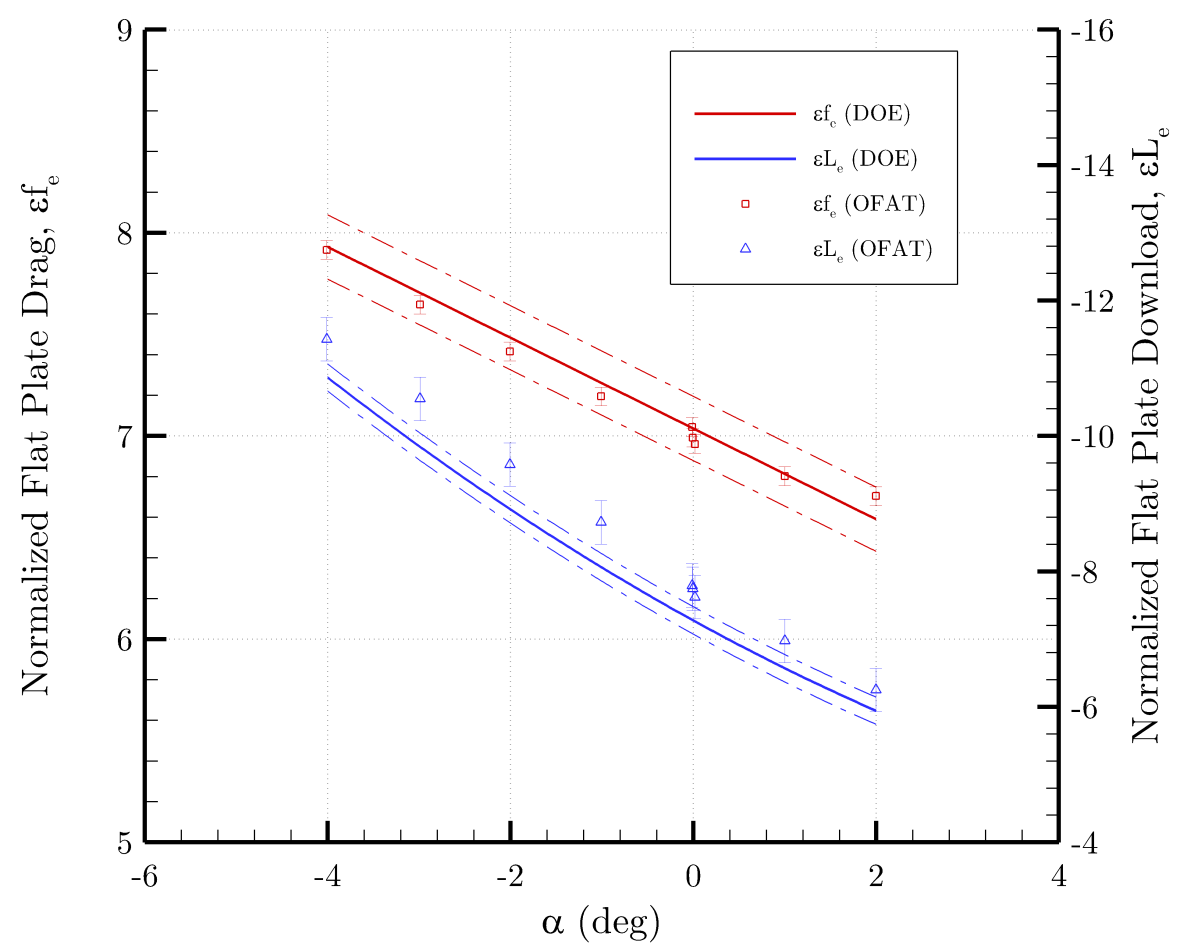

(a) Pitch Sweep

$\mu=0.30 \quad \mathrm{C}_{\mathrm{T}}=0.007 \quad \alpha=0.0$

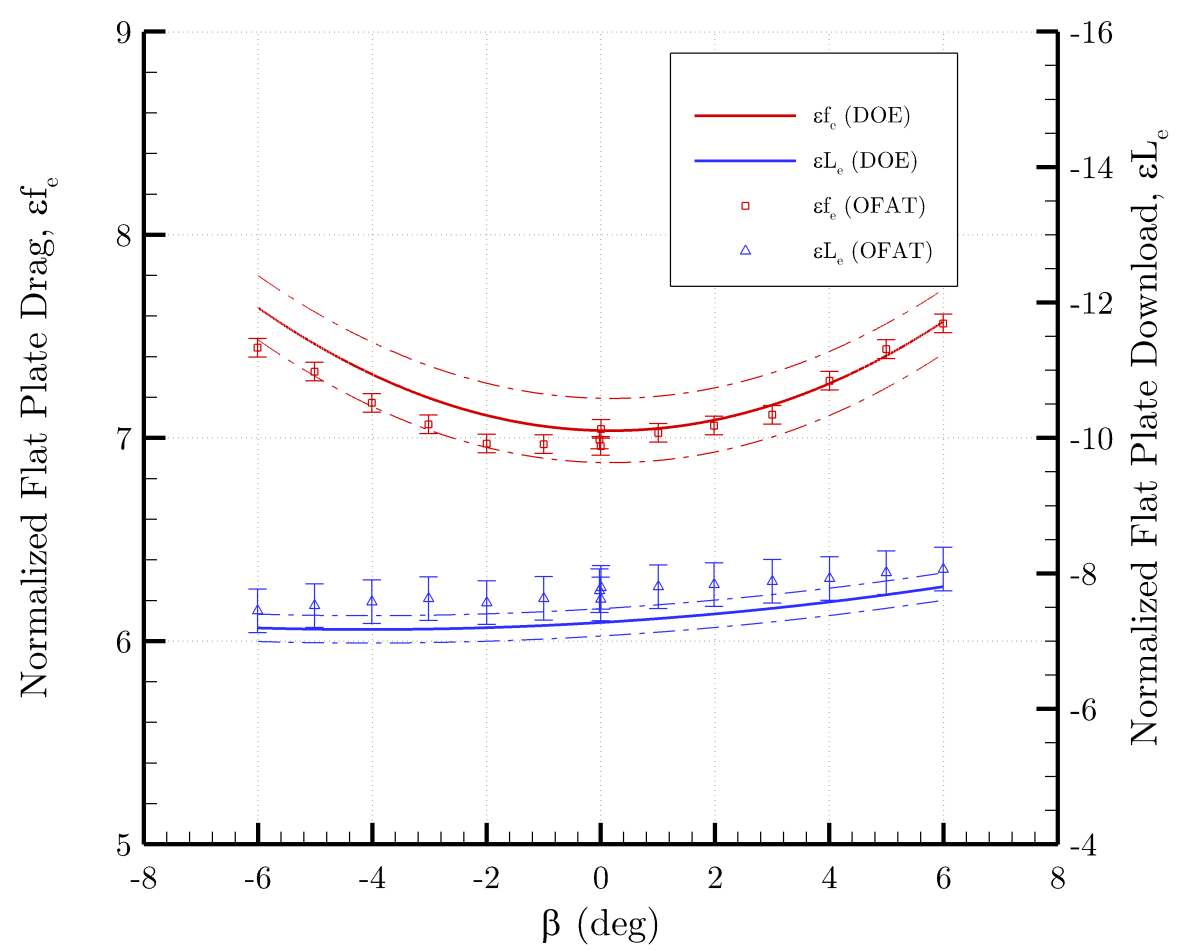

(b) Sideslip Sweep

Figure 9: DOE surface response model compared to experimental OFAT data points, $\mu=0.30, C_{T}=0.007$. 12 of 20 


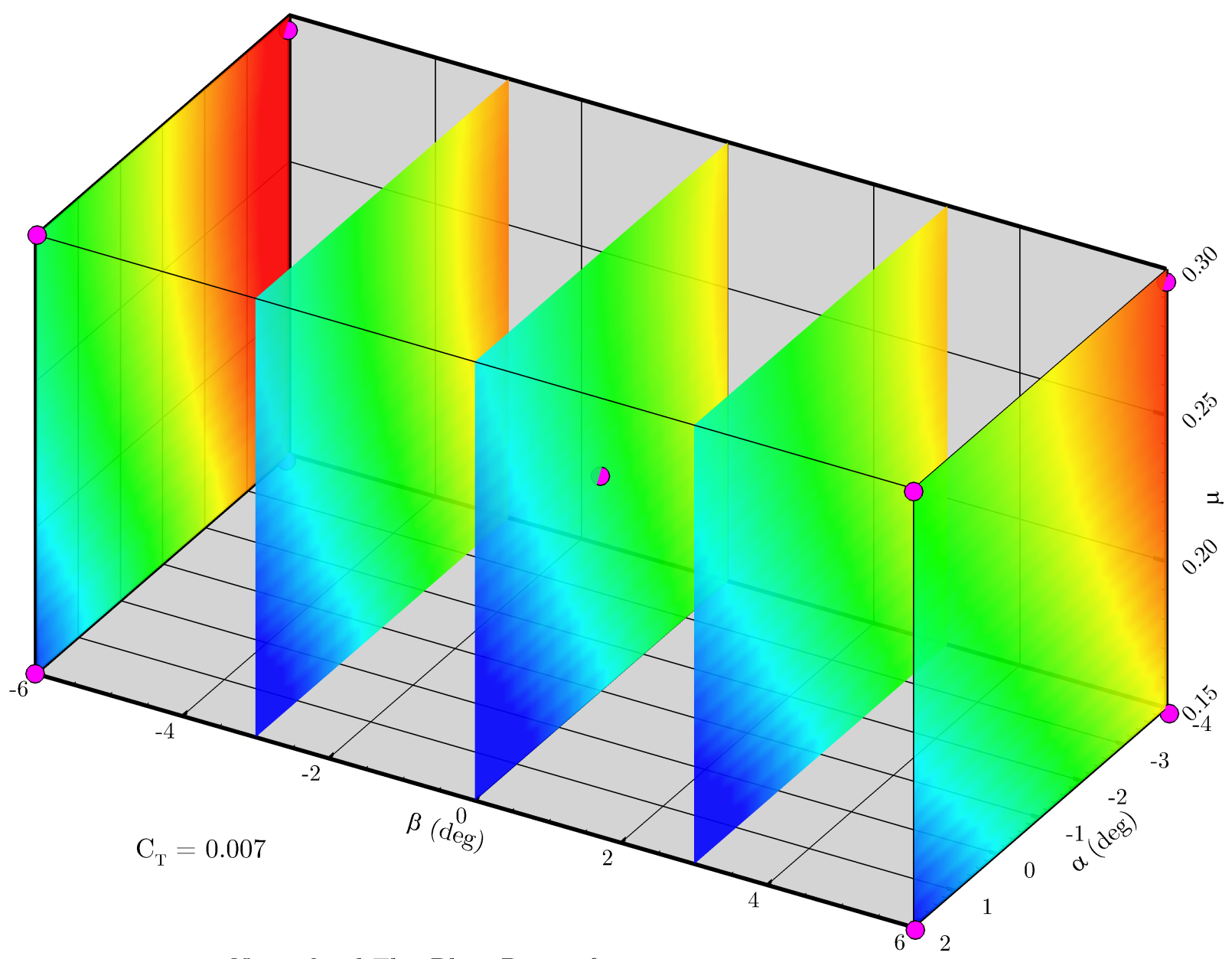

Normalized Flat Plate Drag, $\varepsilon_{\mathrm{e}}$

$\begin{array}{lllllllllll}6.00 & 6.25 & 6.50 & 6.75 & 7.00 & 7.25 & 7.50 & 7.75 & 8.00 & 8.25 & 8.50\end{array}$

Figure 10: DOE drag surface response model of the OH-58F at $C_{T}=0.007$. 


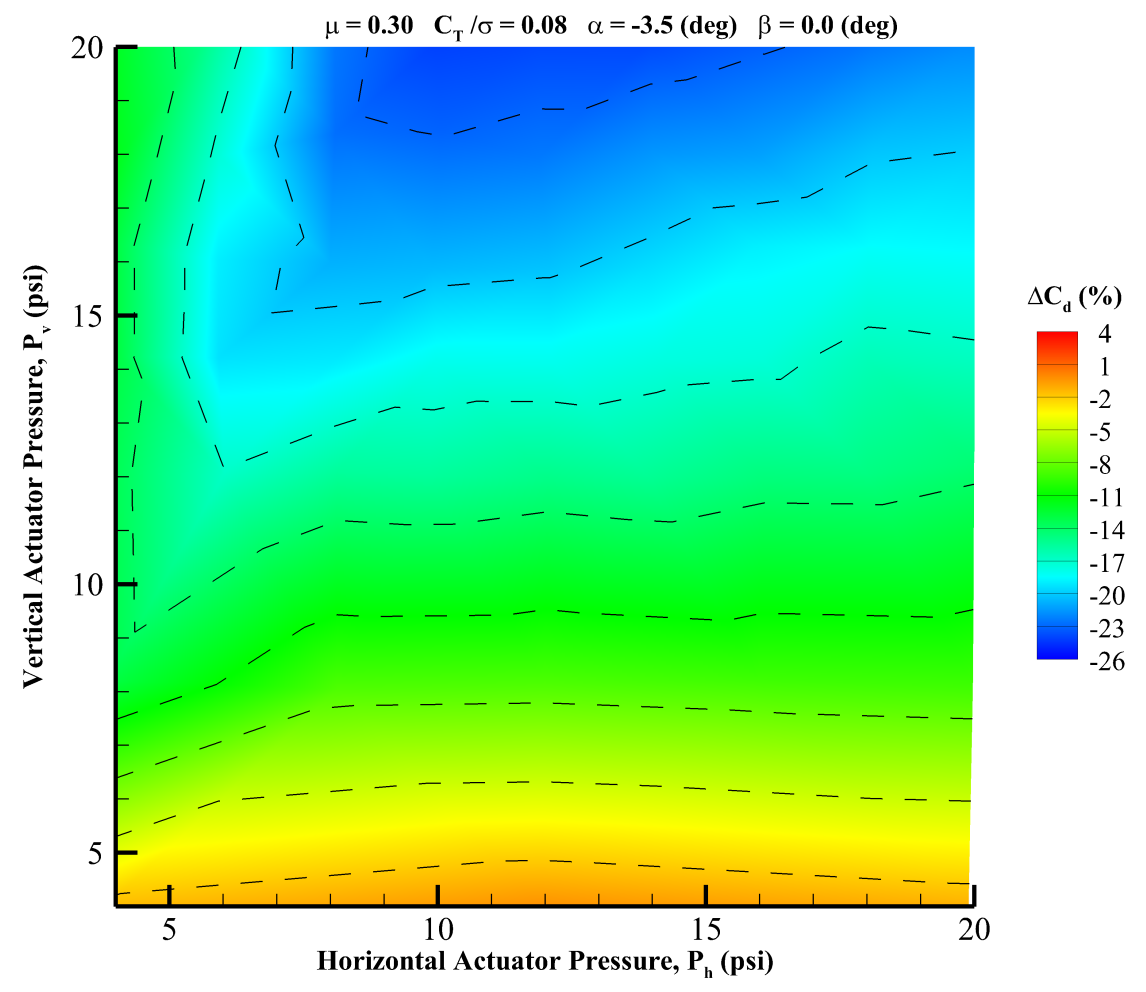

(a) OFAT Data

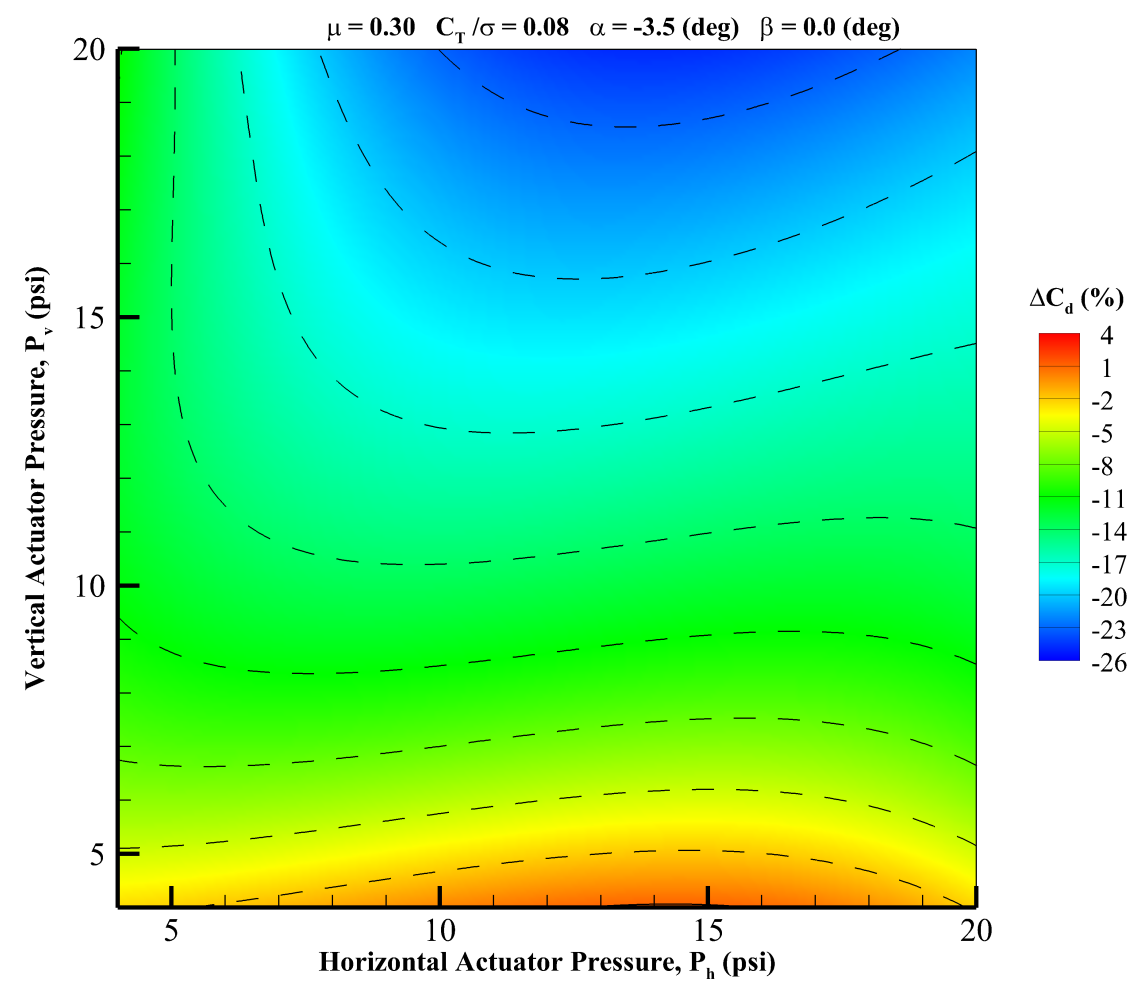

(b) DOE Model

Figure 11: Comparison of AFC drag reduction: DOE model and OFAT data for, $\mu=0.30, \alpha=-3.5^{\circ}$. 
a) $P_{v}=20$ psi $P_{h}=5$ psi

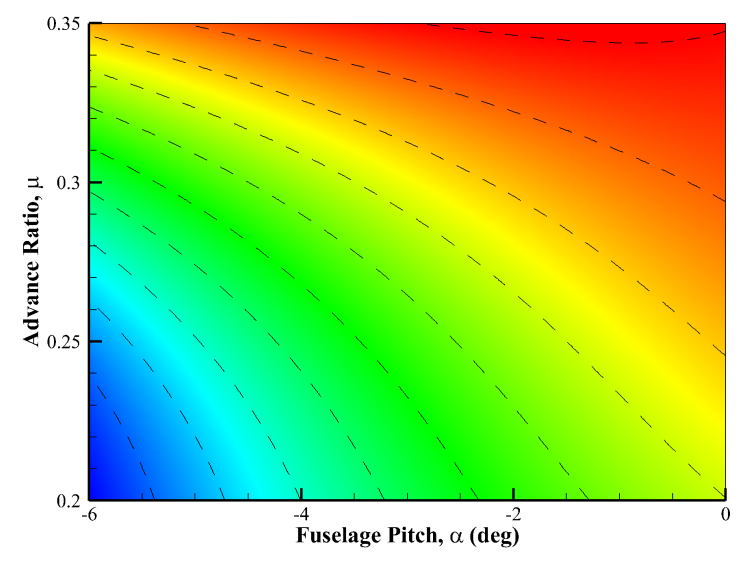

c) $P_{v}=20$ psi $P_{h}=15$ psi

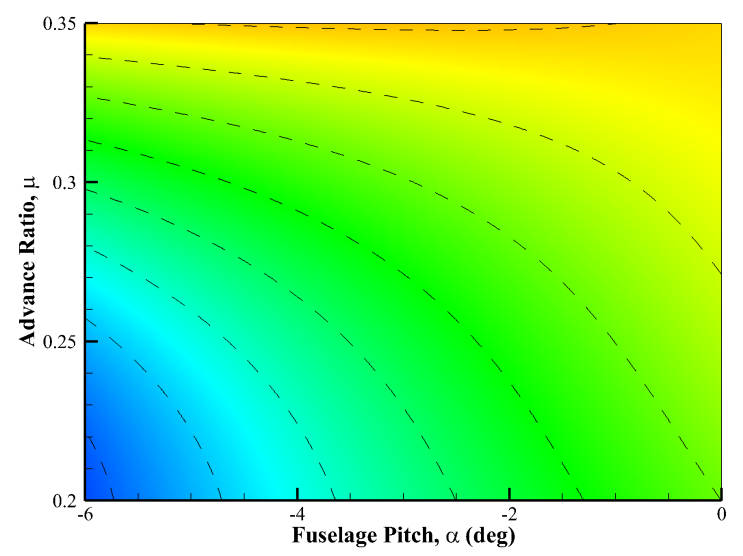

b) $P_{v}=20$ psi $P_{h}=10 p s i$

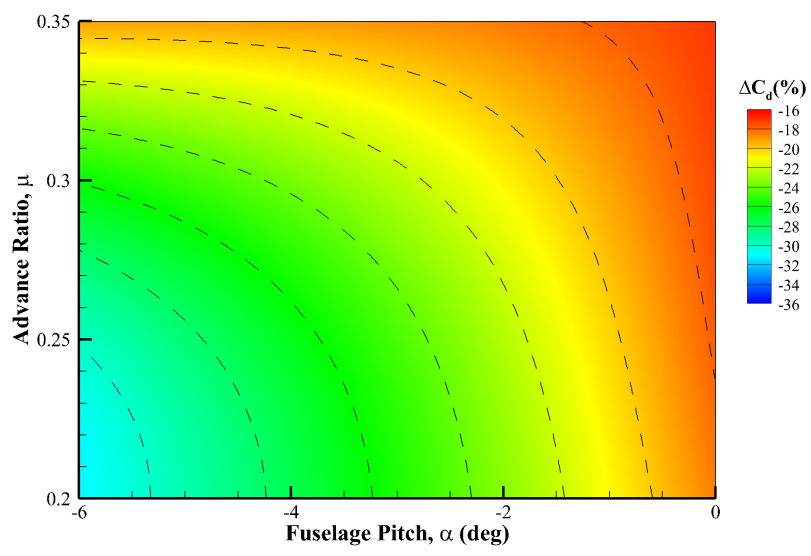

d) $P_{v}=20$ psi $P_{h}=20$ psi

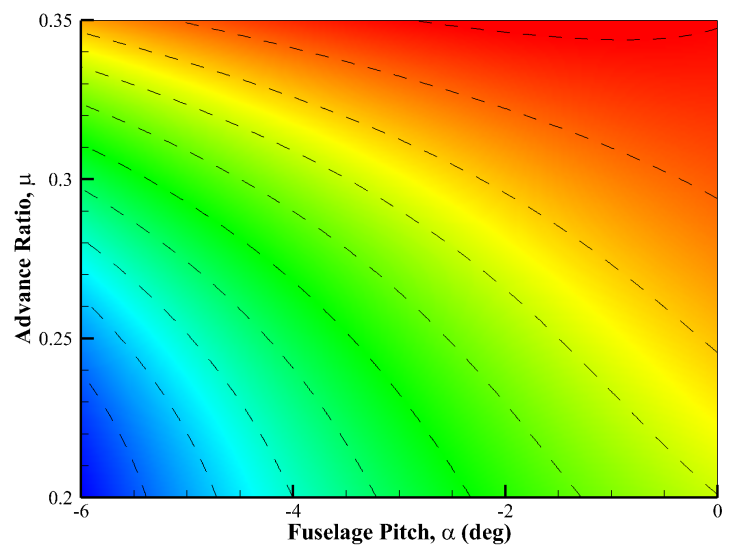

Figure 12: AFC DOE surface response model for varying horizontal actuator pressures.

\section{Appendix}

Table 1: Run Schedule for OH-58F Test, OFAT Test Matrix

\begin{tabular}{cccccc} 
Schedule & Parameter Schedule Definition & $\mu$ & $\alpha(\mathrm{deg})$ & $\beta(\mathrm{deg})$ & $C_{T}$ \\
\hline \hline V1 & $0.20,0.25,0.30,0.35$ & - & 0 & 0 & 0.007 \\
A1 & $0,-2,-4,-3,-1,1,2,0$ & 0.30 & - & 0 & 0.007 \\
B1 & $0,-2,-4,-6,-5,-3,-1,2,4,6,5,3,1,0$ & 0.30 & 0 & - & 0.007 \\
\hline
\end{tabular}


Table 2: DOE Independent Variable Ranges for OH-58F Case Study

\begin{tabular}{ccccc} 
Parameter & $\mu$ & $\alpha(\mathrm{deg})$ & $\beta(\mathrm{deg})$ & $C_{T}$ \\
\hline \hline $\min (\zeta)$ & 0.15 & -4.0 & -6.0 & 0.0035 \\
$\max (\zeta)$ & 0.30 & 2.0 & 6.0 & 0.0070 \\
\hline
\end{tabular}

Table 3: DOE Independent Variable Ranges for AFC Case Study

\begin{tabular}{ccccc} 
Parameter & $\mu$ & $\alpha(\mathrm{deg})$ & $P_{v}(p s i)$ & $P_{h}(p s i)$ \\
\hline \hline $\min (\zeta)$ & 0.20 & -6.0 & 4.0 & 4.0 \\
$\max (\zeta)$ & 0.35 & 0.0 & 20.0 & 20.0 \\
\hline
\end{tabular}

Table 4: DOE OH-58F Coefficients

\begin{tabular}{ccc}
$x_{i}$ & $\varepsilon f_{e}$ & $\varepsilon L_{e}$ \\
\hline \hline 1 & 7.31 & -8.24 \\
$\alpha$ & -0.79 & 2.66 \\
$\beta$ & -0.04 & -0.18 \\
$\mu$ & 0.23 & 0.00 \\
$C_{T}$ & -0.23 & -0.23 \\
$\alpha \beta$ & 0.11 & -0.17 \\
$\alpha \mu$ & 0.21 & -0.19 \\
$\alpha C_{T}$ & -0.09 & 0.19 \\
$\beta \mu$ & 0.09 & -0.11 \\
$\beta C_{T}$ & -0.04 & 0.00 \\
$\mu C_{T}$ & 0.13 & 0.09 \\
$\alpha^{2}$ & 0.00 & -0.34 \\
$\beta^{2}$ & 0.57 & -0.22 \\
$\mu^{2}$ & -0.18 & -0.26 \\
$C_{T}^{2}$ & 0.00 & 0.00 \\
$\alpha \beta \mu$ & 0.00 & 0.10 \\
$\alpha \mu C_{T}$ & 0.00 & -0.19 \\
$\mu C_{T}^{2}$ & 0.00 & 0.57 \\
\hline
\end{tabular}

16 of 20

American Institute of Aeronautics and Astronautics 


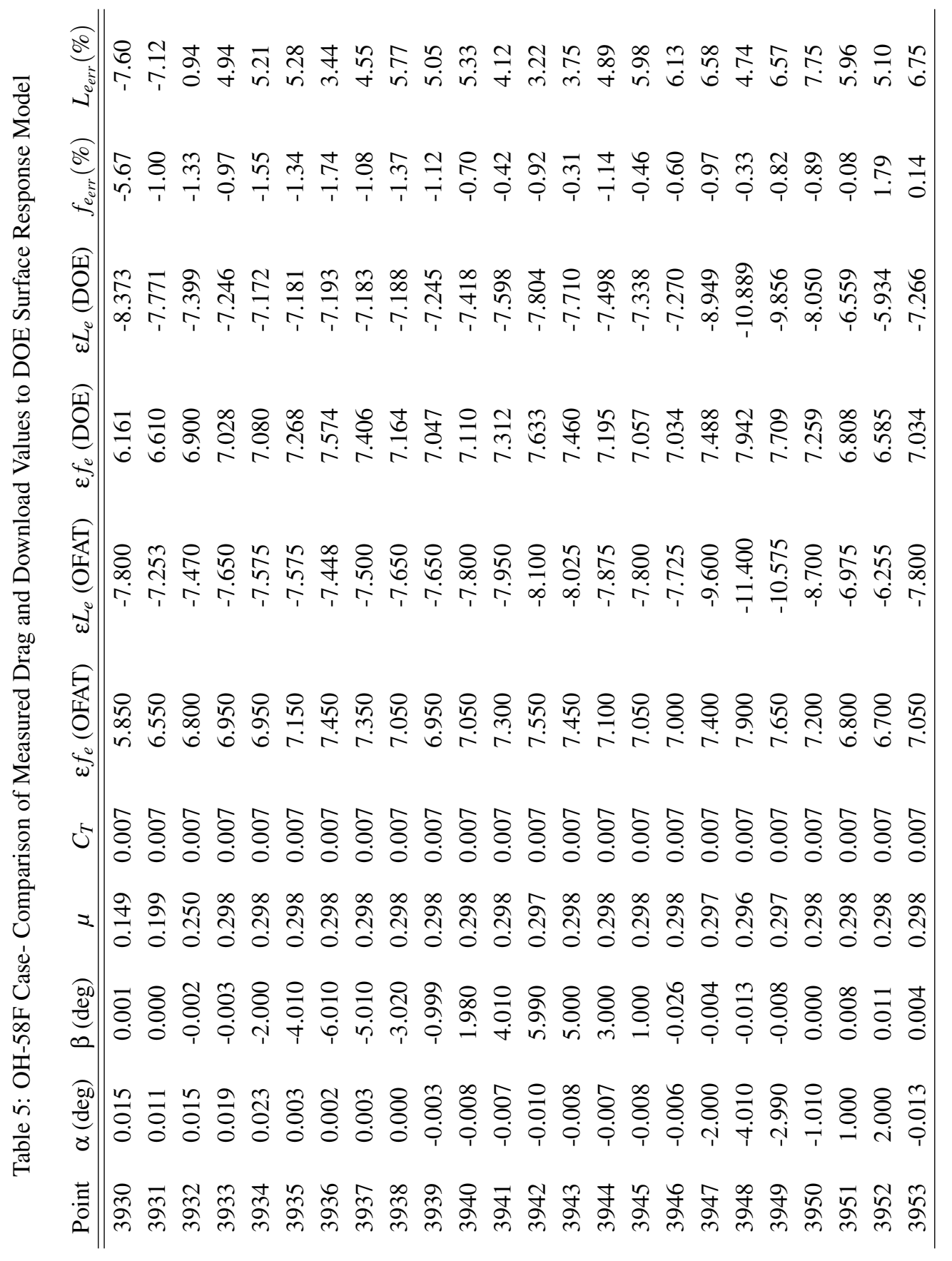

17 of 20 
Table 6: DOE AFC Coefficients

\begin{tabular}{cc}
$x_{i}$ & $\Delta C_{d}(\%)$ \\
\hline \hline 1 & -17.87 \\
$\mu$ & 7.73 \\
$\alpha$ & 3.78 \\
$P_{v}$ & -9.68 \\
$P_{h}$ & 0.00 \\
$\mu \alpha$ & -2.65 \\
$\mu P_{v}$ & -2.23 \\
$\mu P_{h}$ & 1.90 \\
$\alpha P_{v}$ & 0.00 \\
$\alpha P_{h}$ & -2.11 \\
$P_{v} P_{h}$ & -2.86 \\
$\mu^{2}$ & -1.10 \\
$\alpha^{2}$ & -3.07 \\
$P_{v}^{2}$ & 4.87 \\
$P_{h}^{2}$ & 3.00 \\
$\mu \alpha P_{v}$ & 0.00 \\
$\mu \alpha P_{h}$ & 0.00 \\
$\mu P_{v} P_{h}$ & 0.00 \\
$\alpha P_{v} P_{h}$ & 0.00 \\
$\mu^{2} \alpha$ & -1.67 \\
$\mu^{2} P_{v}$ & 2.55 \\
$\mu^{2} P_{h}$ & 0.00 \\
$\mu \alpha^{2}$ & 0.00 \\
$\mu P_{v}^{2}$ & -1.68 \\
$\mu P_{h}^{2}$ & 0.00 \\
$\alpha^{2} P_{v}$ & 3.32 \\
$\alpha^{2} P_{h}$ & -1.78 \\
$\alpha P_{v}^{2}$ & 0.81 \\
$\alpha P_{h}^{2}$ & 3.51 \\
$P_{v}^{2} P_{h}$ & -1.41 \\
$P_{v} P_{h}^{2}$ & 5.60 \\
$\mu^{3}$ & 0.00 \\
$\alpha^{3}$ & 0.00 \\
$P_{v}^{3}$ & -2.57 \\
$P_{h}^{3}$ & -2.29 \\
\hline &
\end{tabular}

18 of 20

American Institute of Aeronautics and Astronautics 
Table 7: AFC DOE Case Study Results- $\alpha=-3.5^{\circ}, \mu=0.30$

\begin{tabular}{cccccc} 
Point & $P_{v}$ & $P_{h}$ & $\Delta C_{d}(\%)(\mathrm{OFAT})$ & $\Delta C_{d}(\%)(\mathrm{DOE})$ & $(\%)$ Diff \\
\hline \hline 2754 & 20.0 & 10.0 & -24.1 & -23.0 & -1.1 \\
2757 & 20.2 & 3.9 & -11.9 & -10.4 & -1.4 \\
2758 & 20.2 & 5.9 & -15.6 & -16.3 & 0.7 \\
2759 & 20.2 & 8.1 & -22.4 & -20.7 & -1.7 \\
2760 & 20.3 & 11.9 & -24.2 & -24.7 & 0.5 \\
2761 & 20.1 & 13.9 & -23.9 & -24.9 & 0.9 \\
2762 & 20.3 & 16.1 & -23.6 & -24.7 & 1.1 \\
2763 & 20.1 & 18.1 & -22.8 & -23.5 & 0.7 \\
2764 & 20.3 & 20.1 & -22.2 & -22.3 & 0.1 \\
2768 & 18.0 & 4.1 & -11.9 & -11.5 & -0.4 \\
2769 & 18.0 & 5.9 & -17.5 & -15.9 & -1.6 \\
2770 & 18.1 & 8.1 & -22.7 & -19.5 & -3.2 \\
2771 & 18.3 & 10.1 & -23.1 & -21.6 & -1.5 \\
2772 & 17.9 & 11.9 & -22.4 & -22.1 & -0.2 \\
2773 & 18.0 & 14.0 & -21.6 & -22.4 & 0.8 \\
2774 & 18.0 & 16.0 & -21.2 & -21.9 & 0.7 \\
2775 & 18.0 & 18.1 & -20.3 & -21.0 & 0.7 \\
2776 & 18.0 & 20.1 & -19.9 & -19.9 & 0.0 \\
2780 & 16.2 & 4.0 & -13.0 & -11.9 & -1.1 \\
2781 & 15.9 & 5.9 & -19.0 & -15.6 & -3.4 \\
2782 & 15.9 & 8.0 & -20.8 & -18.2 & -2.6 \\
2783 & 15.9 & 9.9 & -20.5 & -19.6 & -0.9 \\
2784 & 15.9 & 12.1 & -20.1 & -20.2 & 0.0 \\
2785 & 15.9 & 13.9 & -19.5 & -20.1 & 0.6 \\
2786 & 16.1 & 15.9 & -18.9 & -19.8 & 0.9 \\
2787 & 16.0 & 18.0 & -18.5 & -18.9 & 0.5 \\
2788 & 15.8 & 20.1 & -18.3 & -18.0 & -0.3 \\
2792 & 14.1 & 4.1 & -13.2 & -12.4 & -0.8 \\
2793 & 14.2 & 5.9 & -19.3 & -15.2 & -4.1 \\
2794 & 14.0 & 8.0 & -19.0 & -17.1 & -1.9 \\
2795 & 14.1 & 10.0 & -18.1 & -18.1 & 0.0 \\
2796 & 14.0 & 12.1 & -18.1 & -18.3 & 0.2 \\
2797 & 14.0 & 14.1 & -17.6 & -18.0 & 0.4 \\
2798 & 14.1 & 16.0 & -17.5 & -17.6 & 0.1 \\
2799 & 14.0 & 18.0 & -16.4 & -17.0 & 0.6 \\
2800 & 14.1 & 20.0 & -16.6 & -16.6 & 0.0 \\
2804 & 12.0 & 3.9 & -13.4 & -12.1 & -1.3 \\
2805 & 12.1 & 6.0 & -16.8 & -14.4 & -2.4 \\
2806 & 12.1 & 8.1 & -15.5 & -15.6 & 0.1 \\
2807 & 12.0 & 9.8 & -15.6 & -15.9 & 0.3 \\
2808 & 11.9 & 12.0 & -15.0 & -15.8 & 0.9 \\
2809 & 12.0 & 13.9 & -15.3 & -15.7 & 0.3 \\
& 12.0 & 16.1 & -14.6 & -15.2 & 0.6 \\
& 12.0 & 18.0 & -14.8 & -14.9 & 0.1 \\
& & & & &
\end{tabular}

19 of 20 
Table 7 Continued: AFC DOE Case Study Results- $\alpha=-3.5^{\circ}, \mu=0.30$

\begin{tabular}{cccccc} 
Point & $P_{v}$ & $P_{h}$ & $\Delta C_{d}(\%)(\mathrm{OFAT})$ & $\Delta C_{d}(\%)(\mathrm{DOE})$ & $(\%)$ Diff \\
\hline \hline 2812 & 12.1 & 20.0 & -14.5 & -15.0 & 0.5 \\
2815 & 8.1 & 3.8 & -13.1 & -9.6 & -3.5 \\
2816 & 8.0 & 8.1 & -8.6 & -10.4 & 1.7 \\
2817 & 8.1 & 12.0 & -8.7 & -9.7 & 1.0 \\
2818 & 8.1 & 16.0 & -9.2 & -9.2 & -0.1 \\
2819 & 8.1 & 20.0 & -9.1 & -10.4 & 1.3 \\
2822 & 4.0 & 3.9 & -1.7 & -2.5 & 0.8 \\
2823 & 4.0 & 11.9 & -0.3 & 1.0 & -1.2 \\
2824 & 4.0 & 19.9 & -1.2 & -2.2 & 1.1 \\
\hline
\end{tabular}

